\title{
Muscular Contraction Ability Develops in the Lower Trapezius Muscle of the Dominant Arm in Team Hand-Ball Players
}

\author{
Hajime Fujimoto1,2, Tamotsu Yabumoto², Hiroyuki Sugimori², Sohee Shin'2, \\ Tsuneo Watanabe ${ }^{2}$, Toshio Matsuoka ${ }^{2}$ \\ ${ }^{1}$ Faculty of Health and Sport Sciences, University of Tsukuba, Tsukuba, Japan \\ ${ }^{2}$ Department of Sports Medicine and Sports Science, Gifu University School of Medicine, Gifu, Japan \\ Email: yabumoto@gifu-u.ac.jp
}

Received 24 April 2015; accepted 17 May 2015; published 20 May 2015

Copyright (C) 2015 by authors and Scientific Research Publishing Inc.

This work is licensed under the Creative Commons Attribution International License (CC BY). http://creativecommons.org/licenses/by/4.0/

c) (i) Open Access

\begin{abstract}
Eleven male university team hand-ball players ( 22 shoulders) with 5 or more years of competitive team hand-ball experience who had no history of injuries were included in this study. We compared the thickness of the trapezius muscle between their dominant arm and non-dominant arm, to clarify the correlation between the muscle thickness and muscular strength during internal and external rotation in the shoulder joints used to throw a handball. We measured the thickness of the middle and lower trapezius muscles at an abduction angle of $90^{\circ}$ descending by the ultrasonic LOGIQ e and measured internal and external rotational muscular strength of the glenohumeral joint by BIODEX. The players showed significantly greater thickness of the lower trapezius muscle during constriction in the dominant arm than that in the non-dominant arm. Furthermore, a positive correlation was observed between muscle thickness of the lower trapezius muscle and the muscular strength during internal rotation of the glenohumeral joint. It is highly probable that the height of the constricting ability in the lower trapezius muscle in the dominant arm is related to the prevention of throwing injuries.
\end{abstract}

\section{Keywords}

Muscle Thickness, Muscle Strength, Throwing Injuries, Internal Rotation, Glenohumeral Joint, Correlation

\section{Introduction}

The prevention of throwing injuries of the shoulder is important in team hand-ball competition, because team

How to cite this paper: Fujimoto, H., Yabumoto, T., Sugimori, H., Shin, S., Watanabe, T. and Matsuoka, T. (2015) Muscular Contraction Ability Develops in the Lower Trapezius Muscle of the Dominant Arm in Team Hand-Ball Players. Advances in Bioscience and Biotechnology, 6, 368-374. http://dx.doi.org/10.4236/abb.2015.65036 
hand-ball athletes tend to use a wider range of different types of throwing than players of other sports; hence, overhand stress occurs, and a dynamic mechanism for shoulder joint stabilisation is required to prevent shoulder joint injuries. One of the dynamic stabilizations for the shoulder is the stabilizing of the scapula by means of trapezius muscle movement during throwing. Instability of the scapula has often been reported to be related to throwing injuries [1]-[3].

Several kinematical studies have investigated means to improve performance of the diverse range of throwing motions carried out by team hand-ball players [4]-[8]. To reduce the risk of throwing injuries, despite the diverse range of motions, preventive medical knowledge of the scapular motions is required to minimise the burden on joint structures and achieve the most effective throwing motion. The trapezius muscle, one of the muscles around the scapula, is split into three fibrous parts comprising the first, middle and lower, and each part serves a different function. The lower trapezius muscle in particular holds the upward rotational position of the scapula and contributes to stabilizing the glenohumeral joints during throwing motions [9]. In competitions, team hand-ball athletes often raise the upper arm while holding the ball and frequently repeat passing and shooting motions. Furthermore, as the ball is heavier than a baseball, the burden on the shoulder joint is likely to be greater than that in baseball. Continued experience of this type of action may affect trapezius muscle thickness. However, no studies have investigated the muscles surrounding the scapula with the aim of preventing injuries of team handball players.

Therefore, in this study, we targeted athletes with 5 or more years of team hand-ball experience who had no history of injuries and compared the thickness of the trapezius muscle between their dominant arm and nondominant arm, to clarify the correlation between the muscle thickness and muscular strength during internal and external rotation in the shoulder joints used to throw a handball.

\section{Methods}

\subsection{Participants (Table 1)}

Eleven male university team hand-ball players (22 shoulders) who belonged to the Tokai Student Team Handball varsity league and had played competitive team hand-ball for 5 or more years were included in this study. Participants were excluded if they met any of the following criteria: 1) complained of shoulder pain, 2) had a history of shoulder joint disorder based on physician diagnosis, and 3) examination showed a throwing disorder (positive Neer sign and Hawkins-Kennedy sign). Participants provided written consent by signing a research consent form that explained the ethical considerations, research details, purpose, methods and important notes with regard to the study.

\subsection{Measurement Details}

\subsubsection{Measurement of Muscle Thickness}

As the measuring device, we used the ultrasonic LOGIQ e (manufactured by GE Health Corporation). We also used 5-MHz sounding probes. There were four measurement positions: the middle trapezius muscle and lower trapezius muscle of both the throwing arm and non-throwing arm. We measured muscle thickness at each point both in a rest position without allowing the muscle to contract as well as when constricted, with the goal of isometric contraction. The measurement position was at an abduction angle of $90^{\circ}$ descending past the elbow off the edge of the bed, which we called the 2nd position (Figure 1). A physical therapist with at least 5 years of clinical experience performed the ultrasonic measurements and determined the measurement positions of the middle and lower trapezius muscle. Measurement positions were based on the report by O'Sullivan et al. [10], and for the middle trapezius muscle, we measured the thickest portion of the venter parallel to the first thoracic vertebrae. For the lower trapezius muscle, we measured $3 \mathrm{~cm}$ outside the spinous process parallel to the eighth thoracic vertebra. To verify the reliability of ultrasonic measurements, we randomly selected 6 of the 11 participants and performed the same measurement twice in 1 week using intraclass correlation coefficient verification.

\subsubsection{Muscular Strength Assessment}

We used isokinetic muscular strength measuring equipment (BIODEX; manufactured by Biodex Medical System) and measured the internal and external rotational muscular strength with the shoulder joint at a $90^{\circ}$ abduction angle (referred to as the 2 nd position). The measurement position was in a sitting position on the sheet of 


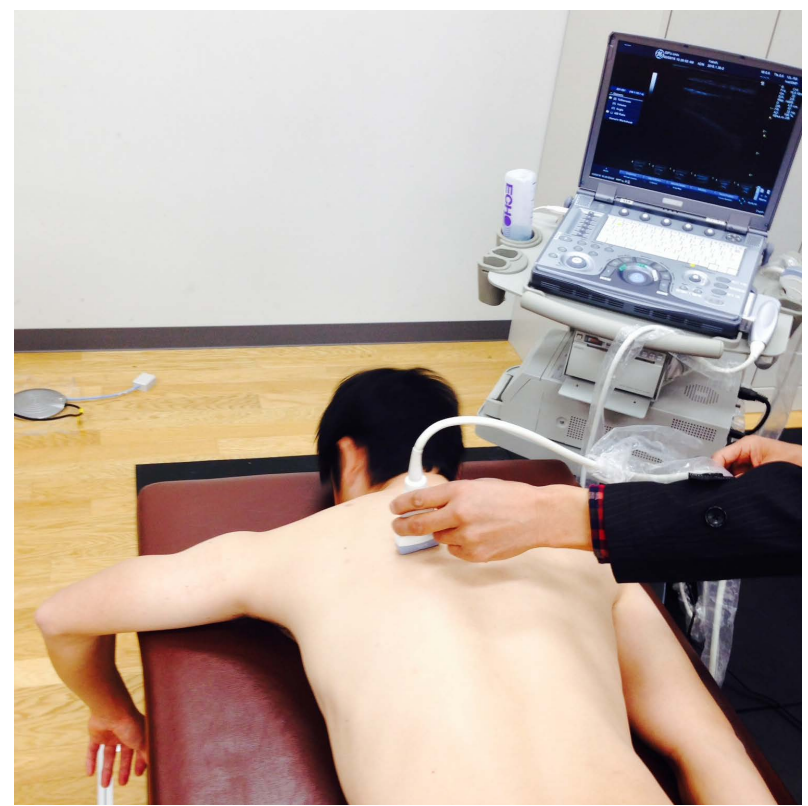

Figure 1. The measurement position.

Table 1. Physique characteristics of the participants.

\begin{tabular}{|c|c|c|c|c|c|c|c|}
\hline & age & $\begin{array}{l}\text { height } \\
(\mathrm{cm})\end{array}$ & $\begin{array}{l}\text { weight } \\
(\mathrm{kg})\end{array}$ & $\begin{array}{c}\text { body fat } \\
(\%)\end{array}$ & BMI & $\begin{array}{c}\text { competitive } \\
\text { experience (year) }\end{array}$ & dominant arm \\
\hline 1 & 19 & 173 & 71.8 & 16.3 & 24.0 & 5 & Rt \\
\hline 2 & 19 & 174 & 71.6 & 17.6 & 23.6 & 5 & Rt \\
\hline 3 & 20 & 174 & 59.1 & 10.9 & 19.5 & 6 & $\mathrm{Lt}$ \\
\hline 4 & 20 & 183 & 76.6 & 16.9 & 22.9 & 6 & Rt \\
\hline 5 & 20 & 182 & 68.0 & 13.3 & 20.5 & 6 & Rt \\
\hline 6 & 22 & 171 & 70.3 & 18.8 & 24.0 & 8 & Rt \\
\hline 7 & 22 & 176 & 66.9 & 14.3 & 21.6 & 8 & Rt \\
\hline 8 & 22 & 177 & 68.3 & 15.8 & 21.8 & 8 & Rt \\
\hline 9 & 20 & 170 & 64.4 & 17.3 & 22.3 & 6 & Rt \\
\hline 10 & 20 & 175 & 66.3 & 16 & 21.6 & 6 & Rt \\
\hline 11 & 22 & 160 & 60.7 & 15.8 & 23.7 & 8 & Rt \\
\hline Mean & 20.3 & 173 & 66.3 & 15.4 & 22.1 & 6.5 & \\
\hline SD & 1.3 & 6.3 & 5.7 & 2.2 & 1.5 & 1.2 & \\
\hline
\end{tabular}

the measuring device, and the trunk of the body and pelvis were fixated with a belt. When the soles of the participants' feet came off the ground, they grasped a fixed lever with the non-testing arm. This was measured successively, left then right, in 2 nd position, with a 60 -second rest in between. Measured actions included rotation of the shoulder joint five times using as large a motion as possible. With the aim of encouraging the participants to exert maximum muscular strength, the same measurer offered all participants verbal encouragement during the motions. Although great variation in the angular velocity from $60^{\circ}-450^{\circ} / \mathrm{sec}$ was seen in previous studies, [11]-[17], in this study, we set the angular velocity at $300 \% \mathrm{sec}$, which is a functional speed equivalent to throwing actions according to Wilk et al.'s classification [15]. Measurement parameters were maximum internal and external torque and mean torque calculated automatically from the average of 5 measured values. 


\subsubsection{Statistical Analysis}

We used the Mann-Whitney $U$ test to compare data for the dominant and non-dominant arms. We calculated the Pearson product-moment correlation coefficient for the relation between muscle strength and muscle thickness. The statistically significant standard for all differences was set at less than $5 \%$. We used SPSS II for Windows 11.0.1J (SPSS Inc.) for statistical analysis.

\section{Results}

\subsection{Muscle Thickness}

The reliability results are shown in Table 2. The reliability for execution was good. The sizes of the middle and lower trapezius muscles are shown in Table 3. Muscle thickness of the lower trapezius muscle when constricted was significantly greater in the dominant arm than in the non-dominant arm $(\mathrm{p}<0.05)$. No significant difference in the thickness of the middle trapezius muscle was found between the dominant arm and non-dominant arm.

\subsection{Muscle Strength}

Table 4 shows the maximum and average torque values of internal and external rotation with the shoulder joint in the 2 nd position. There were no significant differences found in the maximum and average torque between the dominant and non-dominant arm under these circumstances.

\subsection{Correlation between Muscle Thickness and Muscular Strength}

Figure 2 shows the relation between trapezius muscle thickness and internal rotational muscular strength during shoulder joint rotation. The correlation coefficient for the lower trapezius muscle thickness and the maximum

Table 2. The reliability of ultrasonic measurement.

\begin{tabular}{lccccccrr}
\multicolumn{2}{c}{ 1st trial } & \multicolumn{2}{c}{ 2nd trial } & \multicolumn{3}{c}{ 3rd trial } \\
\hline mean & SD & mean & SD & mean & SD & ICC & F-value \\
3.80 & 0.57 & 3.89 & 0.54 & 3.92 & 0.59 & 0.94 & 2.41 \\
\hline
\end{tabular}

Note: ICC: Intraclass correlation coefficient; n.s: $>0.05$.

Table 3. The thickness of trapezius muscle tissue.

\begin{tabular}{|c|c|c|c|c|c|c|c|}
\hline & & \multicolumn{3}{|c|}{ dominant arm } & \multicolumn{3}{|c|}{ non-dominant arm } \\
\hline & & rest & contraction & $(\%)$ & rest & contraction & $(\%)$ \\
\hline \multirow{2}{*}{ middle } & mean & 8.4 & 14.0 & 169.4 & 7.0 & 11.9 & 172.8 \\
\hline & $\mathrm{SD}$ & 0.9 & 2.1 & 43.2 & 1.5 & 1.6 & 14.5 \\
\hline \multirow{2}{*}{ lower } & mean & 5.3 & $7.4^{*}$ & 139.6 & 3.9 & 5.2 & 136.9 \\
\hline & $\mathrm{SD}$ & 0.7 & 1.1 & 21.8 & 0.7 & 0.6 & 39.3 \\
\hline
\end{tabular}

${ }_{\mathrm{p}}^{*}<0.05$.

Table 4. The maximum and average torque of rotation.

\begin{tabular}{|c|c|c|c|c|c|c|c|c|c|}
\hline & & \multicolumn{4}{|c|}{ maximum torque/weight } & \multicolumn{4}{|c|}{ mean torque } \\
\hline & & $\begin{array}{l}\text { dominant } \\
\text { arm }\end{array}$ & $\begin{array}{c}\text { non-dominant } \\
\text { arm }\end{array}$ & $\mathrm{z}$ & $\mathrm{p}$ & $\begin{array}{l}\text { dominant } \\
\text { arm }\end{array}$ & $\begin{array}{c}\text { non-dominant } \\
\text { arm }\end{array}$ & $\mathrm{z}$ & $\mathrm{p}$ \\
\hline \multirow{2}{*}{ external } & mean & 29.9 & 28.8 & 0.460 & 0.645 & 18.4 & 17.9 & 0.427 & 0.669 \\
\hline & $\mathrm{SD}$ & 5.4 & 4.6 & & & 5.0 & 3.2 & & \\
\hline \multirow{2}{*}{ internal } & mean & 57.3 & 55.8 & 0.460 & 0.646 & 35.2 & 33.9 & 0.263 & 0.973 \\
\hline & SD & 9.8 & 12.1 & & & 8.4 & 7.9 & & \\
\hline
\end{tabular}




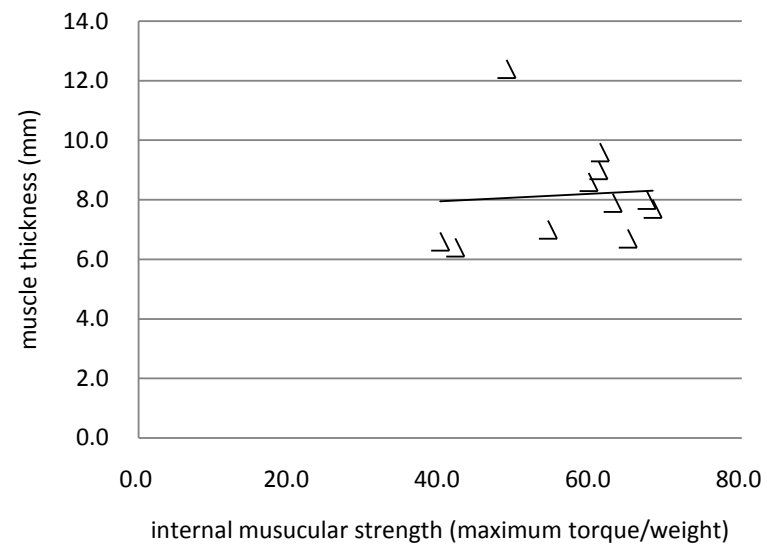

(a)

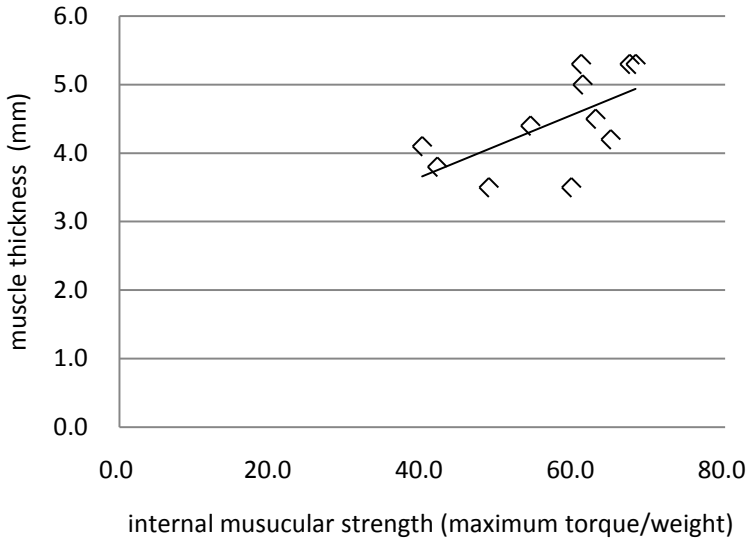

(b)

Figure 2. The correlation between trapezius muscle thickness and muscular strength: (a) middle trapezius; (b) lower trapezius.

torque during shoulder joint rotation was $\mathrm{r}=0.635$, indicating a moderate, positive, significant correlation $(\mathrm{p}<$ 0.05). No significant correlation was found between the middle trapezius muscle thickness and the maximum torque during shoulder joint rotation. In addition, no significant correlation was found between the middle trapezius muscle thickness and the muscular ability during external rotation of the shoulder joint.

\section{Discussion}

Players who have participated in team hand-ball competitions for 5 years or more without developing throwing injuries showed significantly greater muscle thickness during construction in the lower trapezius muscle in the dominant arm compared to the non-dominant arm. Furthermore, a positive correlation was observed between the muscle thickness of the lower trapezius muscle and the maximum torque during internal rotation of the shoulder joint on the throwing side.

First, the constricted muscle thickness of the lower trapezius muscle was significantly thicker on the dominant arm than on the non-dominant arm. On the other hand, there was no significant difference in the muscle thickness value in the middle trapezius muscle between the dominant and non-dominant arm. This shows that mobilization of the lower trapezius muscle is repeated when making throwing motions and improves the muscle constricting ability of the muscle at the bottom of the muscle. This also demonstrates the possibility that the team hand-ball players who participated in this study and had not experienced shoulder joint injuries are performing throwing motions with the scapula in a position of upward rotation. In the upward rotational position of the scapula, for throwing movements that involve elevation of the arm, there is increased structural stability for the scapula and humerus in the glenohumeral joints. The position of the arm in the glenohumeral joint is referred to as the zero position, and the humeral shaft axis is roughly aligned with the scapular spine in this position. This is the relative position of the scapula and humerus that achieves joint stability in fast-moving quadrupeds [18]. Therefore, stability and motion efficiency in the glenohumeral joint is likely high for players with high muscular strength of the lower trapezius muscle when throwing, and this may contribute to the prevention of glenohumeral joint injuries.

Second, a positive correlation was observed between the muscle thickness of the lower trapezius muscle and the maximum torque during internal rotation of the shoulder joint on the throwing side. No significant correlation was found between the thickness of the middle trapezius muscle and the maximum torque during internal shoulder joint rotation on the throwing side. This shows that stabilisation of the upward rotation of the scapula due to the lower trapezius muscle while throwing is related to exertion of internal rotation muscular strength in the shoulder joint. For the scapula at the upper arm joint, in the horizontal abduction in the final area, the abduction and external rotation movements are limited, because the joint capsule and the ligament are tense. However, in a mild horizontal adduction position, the range of abduction and external rotation expands. When using internal rotation in a throwing motion, it is necessary to expand the area of external rotation by rotating the upper glenohumeral joint inward and parallel, and stability in the upward rotation of the scapula is required. Thus, it 
appears that athletes with a long history of competing and no history of throwing injuries might exhibit a throwing motion that repeatedly reduces excessive abduction and external rotation stress of the scapula at the glenohumeral joint with upward rotation of the scapula to efficiently reflect the internal rotational movement of the glenohumeral joints, On the other hand the strength of the maximum torque when internally rotating the shoulder joint has been reported to have no effect on ball speed [19]. This study also found no significant difference in maximum torque during internal rotation of the shoulder joint, although the value was higher in the dominant arm than in the non-dominant arm. In other words, a dynamic stabilization from the lower trapezius muscle does not directly improve performance parameters such as maximum torque or ball speed, but there is a possibility that it is functional in preventing the excessive mechanical stress to the scapula at the joint that occurs during throwing motions.

As the dominant arm is the throwing side, there is a possibility that the high muscle thickness value on the throwing side reflects the predominance of this side. However, in the middle trapezius muscle, although the muscle thickness was greater on the dominant side than on the non-dominant side, no significant difference was found. A significant difference was only found in the lower, which suggests that there may be a correlation with playing characteristics. This shows the importance of training the trapezius muscle for prevention of throwing injuries by utilizing a Dynamic stabilization for the scapula. The importance of training the muscles around the scapula, including the approach to the trapezius muscle in baseball pitching motions in players returning to competition, has been reported in past studies [20]-[22].

The experiments of this study have three limitations. First, the participants included only team hand-ball athletes with no history of throwing injuries. We were unable to show if there is a difference in the lower muscle thickness in players with throwing injuries and those without. Second, because we did not compare the data to those in players of other sports that involve overhand stress, such as baseball, volleyball and tennis, we are unable to show if these tendencies are unique to team hand-ball. Third, other muscle groups, such as the rotator cuff, exhibit complex effects on movement in a scapula Dynamic stabilization. These results are biased with regard to this point.

\section{Conclusions}

In this study, players involved in team hand-ball competitions for at least 5 years with no history of throwing injuries showed significantly greater thickness of the lower trapezius muscle during constriction in the dominant arm than that in the non-dominant arm. Furthermore, a positive correlation was observed between muscle thickness of the lower trapezius muscle and the muscular strength during internal rotation of the glenohumeral joint. It is highly probable that the height of the constricting ability in the lower trapezius muscle in the dominant arm is related to the prevention of throwing injuries. Future studies should include greater numbers of participants, investigate shoulders with throwing injuries, and make comparisons with other factors.

Players who had participated in team hand-ball competitions for 5 years or more without developing throwing injuries showed significantly greater muscle thickness during construction in the lower trapezius muscle in the throwing arm compared with the non-throwing arm.

\section{References}

[1] Gaber, S., Zdravkovic, V. and Jost, B. (2014) The Throwing Shoulder. Orthopade, 43, 223-229. http://dx.doi.org/10.1007/s00132-013-2144-7

[2] Reinold, M.M. and Curtis, A.S. (2013) Microinstability of the Shoulder in the Overhead Athlete. International Journal of Sports Physical Therapy, 8, 601-616.

[3] Cowderoy, G.A., Lisle, D.A. and O'Connell, P.T. (2009) Overuse and Impingement Syndromes of the Shoulder in the Athlete. Magnetic Resonance Imaging Clinics of North America, 17, 577-593. http://dx.doi.org/10.1016/j.mric.2009.06.003

[4] Van Den Tillaar, R., Zondag, A. and Cabri, J. (2013) Comparing Performance and Kinematics of Throwing with a Circular and Whip-Like Wind Up by Experienced Handball Players. Scandinavian Journal of Medicine \& Science in Sports, 23, e373-e380. http://dx.doi.org/10.1111/sms.12091

[5] Wagner, H., Pfusterschmied, J., Tilp, M., Landlinger, J., von Duvillard, S.P. and Müller, E. (2014) Upper-Body Kinematics in Team-Handball Throw, Tennis Serve, and Volleyball Spike. Scandinavian Journal of Medicine \& Science in Sports, 24, 345-354. http://dx.doi.org/10.1111/j.1600-0838.2012.01503.x 
[6] Van Den Tillaar, R. and Cabri, J.M. (2012) Gender Differences in the Kinematics and Ball Velocity of Overarm Throwing in Elite Team Handball Players. Journal of Sports Sciences, 30, 807-813. http://dx.doi.org/10.1080/02640414.2012.671529

[7] Wagner, H., Buchecker, M., Von Duvillard, S.P. and Müller, E. (2010) Kinematic Comparison of Team Handball Throwing with Two Different Arm Positions. International Journal of Sports Physiology and Performance, 5, 469483.

[8] Wagner, H, Buchecker, M, Von Duvillard, S.P. and Müller, E. (2010) Kinematic Description of Elite vs. Low Level Players in Team-Handball Jump Throw. Journal of Sports Science and Medicine, 9, 15-23.

[9] Boettcher, C.E., Cathers, I. and Ginn, K.A.J. (2010) The Role of Shoulder Muscles Is Task Specific. Journal of Science and Medicine in Sport, 13, 651-656. http://dx.doi.org/10.1016/j.jsams.2010.03.008

[10] O'Sullivan, C., McCarthy Persson, U., Blake, C. and Stokes, M. (2012) Rehabilitative Ultrasound Measurement of Trapezius Muscle Contractile States in People with Mild Shoulder Pain. Manual Therapy, 17, 139-144. http://dx.doi.org/10.1016/j.math.2011.11.003

[11] Hinton, R.Y. (1988) Isokinetic Evaluation of Shoulder Rotational Strength in High School Baseball Pitchers. The American Journal of Sports Medicine, 16, 274-279. http://dx.doi.org/10.1177/036354658801600314

[12] Mikesky, A.E., Edwards, J.E., Wigglesworth, J.K. and Kunkel, S. (1995) Eccentric and Concentric Strength of the Shoulder and Arm Musculature in Collegiate Baseball Pitchers. The American Journal of Sports Medicine, 23, 638-642. http://dx.doi.org/10.1177/036354659502300520

[13] Newsham, K.R., Keith, C.S., Saunders, J.E. and Goffinett, A.S. (1998) Isokinetic Profile of Baseball Pitchers' Internal/External Rotation 180, 300, 450 Degrees.s-1. Medicine \& Science in Sports \& Exercise, 30, 1489-1495. http://dx.doi.org/10.1097/00005768-199810000-00004

[14] Brown, L.P., Niehues, S.L., Harrah, A., Yavorsky, P. and Hirshman, H.P. (1988) Upper Extremity Range of Motion and Isokinetic Strength of the Internal and External Shoulder Rotators in Major League Baseball Players. The American Journal of Sports Medicine, 16, 577-585. http://dx.doi.org/10.1177/036354658801600604

[15] Wilk, K.E., Andrews, J.R., Arrigo, C.A., Keirns, M.A. and Erber, D.J. (1993) The Strength Characteristics of Internal and External Rotator Muscles in Professional Baseball Pitchers. The American Journal of Sports Medicine, 21, 61-66. http://dx.doi.org/10.1177/036354659302100111

[16] Sirota, S.C., Malanga, G.A., Eischen, J.J. and Laskowski, E.R. (1997) An Eccentric- and Concentric-Strength Profile of Shoulder External and Internal Rotator Muscles in Professional Baseball Pitchers. The American Journal of Sports Medicine, 25, 59-64. http://dx.doi.org/10.1177/036354659702500111

[17] Ellenbecker, T.S. and Mattalino, A.J. (1997) Concentric Isokinetic Shoulder Internal and External Rotation Strength in Professional Baseball Pitchers. Journal of Orthopaedic \& Sports Physical Therapy, 25, 323-328. http://dx.doi.org/10.2519/jospt.1997.25.5.323

[18] Saha, A.K. (1983) The Classic Mechanism of Shoulder Movements and a Plea for the Recognition of "Zero Position" of Glenohumeral Joint. Clinical Orthopaedics and Related Research, 173, 3-10.

[19] Zapartidis, I., Gouvali, M., Bayios, I. and Boudolos, K. (2007) Throwing Effectiveness and Rotational Strength of the Shoulder in Team Handball. The Journal of Sports Medicine and Physical Fitness, 47, 169-178.

[20] Oliver, G.D., Weimar, W.H. and Plummer, H.A. (2014) Gluteus Medius and Scapula Muscle Activations in Youth Baseball Pitchers. Journal of Strength and Conditioning Research, Published Online. http://journals.lww.com/nsca-jscr http://dx.doi.org/10.1519/jsc.0000000000000797

[21] Matsui, K., Tachibana, T. and Magarey, M. (2014) Motor Control Training for an Amateur Baseball Pitcher with Isolated Paralysis of Trapezius: A Case Report. International Journal of Sports Physical Therapy, 9, 1004-1013.

[22] Trakis, J.E., McHugh, M.P., Caracciolo, P.A., Busciacco, L., Mullaney, M. and Nicholas, S.J. (2008) Muscle Strength and Range of Motion in Adolescent Pitchers with Throwing-Related Pain: Implications for Injury Prevention. The American Journal of Sports Medicine, 36, 2173-2178. http://dx.doi.org/10.1177/0363546508319049 